\title{
Peranan Subduksi terhadap Batuan Volkanik Berusia Neogen di Semenanjung Semporna: Perspektif Petrologi dan Geokimia
}

(Subduction Roles for Neogene Volcanic Rocks in Semporna Peninsula: Petrology and Geochemistry Perspectives)

\author{
ElvaEne JAMES*, AzMAn A. GHAni, JunAidi Asis \& Norbert Simon
}

\begin{abstract}
The Neogene volcanic rocks of Semporna Peninsula is well known for subduction and oIB-like geochemical signature. After the Miocene subduction by the Celebes Sea, subduction-related magmatism was replaced by OIB-like magmatism. The Neogene volcanic rocks in Semporna Peninsula vary from basalt, basaltic andesite, andesite and rhyolite. Major elements and trace elements patterns suggested that the Semporna Peninsula volcanic magma underwent fractional crystallization. From the trend of primitive mantle and REE, 3 types of trends were observed: Subduction-related; depleted Nb, Ta, P, Ti, enrichment of LILE and LREE and depleted in HFSE, OIB-like; enrichment of Nb, Ta and Ti, and MORB; almost flat primitive mantle and REE. The REE patterns also shows the volcanic rocks have Eu negative and positive anomaly, which indicate plagioclase fractionation and plagioclase accumulation. According to the tectonic settings for Semporna Peninsula, the subducted-related volcanic rocks have island arc lavas and plate margin basalt setting. In Triangle $\mathrm{FeO}^{\mathrm{T}}-\mathrm{MgO}-\mathrm{Al}_{2} \mathrm{O}_{3}$, the subducted-related volcanic rocks scattered at the orogeny and spreading center islands areas. The tectonic settings for OIB-like (basalt, 18L5; basaltic andesite, 18L9) and MORB (basaltic andesite, 11L5) volcanic rocks are categorized into within-plate basalt and within-plate lavas which occurred in continental setting (Triangle $\mathrm{FeO}-\mathrm{MgO}-\mathrm{Al}_{2} \mathrm{O}_{3}$ ).
\end{abstract}

Keywords: Neogene; OIB-like; Semporna Peninsula; subduction; volcanic rocks

\section{ABSTRAK}

Batuan volkanik Semenanjung Semporna yang berusia Neogen terkenal dengan ciri-ciri geokimia subduksi dan menyerupai-OIB. Proses subduksi yang berlaku semasa usia Miosen menyebabkan magmatisme kaitan-subduksi diganti dengan magmatisme menyerupai-OIB. Batuan volkanik berusia Neogen di Semenanjung Semporna boleh dibahagi kepada basalt, andesit basalt, andesit dan riolit. Corak yang ditunjukkan oleh unsur major dan unsur surih mencadangkan magma batuan volkanik di Semenanjung Semporna telah mengalami penghabluran berperingkat. Berdasarkan kepada tren daripada mantel primitif dan REE, 3 jenis tren dapat dikenal pasti: Kaitan-subduksi; susutan Nb, Ta, P dan Ti, pengayaan pada LILE dan LREE dan susutan terhadap HFSE, menyerupai-OIB; pengayaan Nb, Ta and Ti, dan MORB; mantel primitif dan REE hampir rata. Pola REE turut menunjukkan batuan volkanik mempunyai nilai anomali Eu negatif dan positif, yang menjelaskan pengfraksian plagioklas dan pengumpulan plagioklas berlaku di dalam magma. Berdasarkan kepada sekitaran tektonik untuk Semenanjung Semporna, batuan volkanik kaitan-subduksi mempunyai sekitaran lava arka kepulauan dan basalt pinggir kepingan. Segitiga $\mathrm{FeO}^{\mathrm{T}}-\mathrm{MgO}-\mathrm{Al}_{2} \mathrm{O}_{3}$ pula menunjukkan batuan volkanik kaitansubduksi tersebar pada kawasan orogeni dan pemuaian pusat kepulauan. Sekitaran tektonik untuk batuan volkanik menyerupai-OIB (basalt, 18L5; andesit basalt, 18L9) dan MORB (andesit basalt, 11L5) ialah basalt dalam-kepingan dan lava dalam-kepingan yang terbentuk di sekitaran benua (Segitiga $\mathrm{FeO}^{\mathrm{T}}-\mathrm{MgO}-\mathrm{Al}_{2} \mathrm{O}_{3}$ ).

Kata kunci: Batuan volkanik; menyerupai-OIB; Semenanjung Semporna; subduksi; usia Neogen

\section{PENGENALAN}

Proses subduksi memainkan peranan yang penting terhadap kejadian arka kepulauan (Shimaoka et al. 2016). Namun, kajian yang lebih mendalam terhadap arka kepulauan menunjukkan kebanyakan arka kepulauan mempunyai komposisi batuan yang pelbagai termasuklah batuan yang mempunyai unsur surih menyerupai Basalt Pulau Lautan (OIB) intrakepingan (Orozco-Esquivel et al. 2007). Ramai pengkaji yang berpendapat bahawa mantel yang bersifat heterogen mempunyai dua jenis asalan magma yang berbeza iaitu magma jenis kaitan-subduksi dan magma
menyerupai-OIB (Gorring \& Kay 2001; Leeman et al. 1990; Orozco-Esquivel et al. 2007).

Di Semenanjung Semporna, batuan volkanik yang berusia Pleistosen lebih menyerupai-OIB daripada berkaitan-subduksi (Macpherson et al. 2010). Ini mungkin disebabkan oleh proses subduksi yang berlaku semasa usia Miosen dan kemudiannya berlakunya penipisan litosfera di bahagian Semenanjung Semporna (Chiang 2002). Hasil penipisan litosfera ini menjadi punca kepada pencetusan lapisan astenosfera untuk mengalir di bahagian atas lithosfera (Chiang 2002) lalu berlakunya penghasilan 
magma yang menyerupai-OIB (Macpherson et al. 2010). Oleh itu, kajian ini dijalankan untuk membincangkan perkaitan antara magma dan sekitaran tektonik batuan volkanik berusia Neogene Semenanjung Semporna.

\section{TEKTONIK DAN GEOLOGI RANTAU}

Pergerakan dan pertembungan plet antara Plet Eurasia, Plet India-Australia dan Plet Pasifik pada masa Senozoik telah membentuk gugusan plet kecil yang sangat kompleks. Di Sabah, batuan dasarnya terbina daripada akresi pecahan blok jujukan ofiolit dan batuan sedimen Paleogen (Hall 2002). Blok jujukan ofiolit ini ditafsirkan sebagai sebahagian daripada kerak lautan kuno yang dikenali sebagai Proto Laut China Selatan. Pada masa Miosen Awal, komples ofiolit ini menjadi batuan dasar bagi batuan arka volkanik yang dikaitkan dengan subduksi berterusan oleh Proto Laut China Selatan pada ketika itu. Pelanggaran berterusan menyebabkan kompleks ini mengalami penyesaran kebelakang yang bertren ke arah Selatan di atas kerak Laut Sulawesi (Mitchell et al. 1986; Rangin 1989). Kompleks ofiolit di bahagaian timur Sabah juga dikelilingi oleh melange yang terbentuk daripada proses runtuhan sedimen, diapir, dan tektonik yang dikaitkan dengan pembukaan lembangan Laut Sulu pada masa penghujung Miosen Awal dan awal Miosen Tengah (Tongkul 1993; Balaguru \& Nichols 2004). Kompleks ofiolit dan melange ini kemudiannya ditindih secara tidak selaras oleh sedimen lembangan membulat yang berusia Miosen Akhir hingga Pliosen. Pada masa Miosen hingga Kuaterner terbentuknya arka volkanik yang menganjur daripada Mindanao di Filipina, Sulu Arkeapelago hingga ke Semenanjung Dent dan Semporna di Sabah (Kirk 1962; Hutchison 2005). Arka volkanik yang tua ditafsirkan terhasil daripada subduksi yang mengarah ke Tenggara (Hall 1996; Hall \& Wilson 2000) manakala volkanik muda pula dikaitkan dengan subduksi Laut Sulawei yang mengarah ke Barat Laut (Hall \& Wilson 2000; Chiang 2002).

\section{GEOLOGI SEMENANJUNG SEMPORNA}

Banjaran volkanik Semenanjung Semporna secara keseluruhannya terdiri daripada asosiasi batuan basaltandesit-dasit-riolit yang berusia Miosen-Pleistosen (Rajah 1). Aktiviti volkanik kawasan ini ditafsirkan bermula pada usia Miosen akibat aktiviti tektonik aktif yang berlaku ketika itu seiring dengan pengendapan fasies-fasies klastik klastik (Hutchison 2005; Sanudin et al. 1995; Shariff \& Sanudin 1995). Penemuan fosil di Tawau dalam unit batu kapur, jelas menunjukkan endapan klastik (Formasi Kalumpang) berusia Miosen Tengah (Junaidi \& Basir 2015). Selain itu, hasil penemuan fosil-fosil di Semenanjung Semporna dan Dent turut menunjukkan bahawa keseluruhan kawasan ini merupakan kawasan tropika yang terdiri daripada sekitaran laut cetek pada masa Miosen Tengah hingga Miosen Akhir (Chung et al. 2015; Junaidi \& Basir 2015). Fasa akhir pembentukan batuan volkanik terdiri daripada aliran basalt olivin dan andesit yang membentuk kubah-kubah kecil di sekitar Semenanjung Semporna (Chiang 2002; Hutchison 2005; Macpherson et al. 2010; Shariff \& Sanudin 1995). Batuan

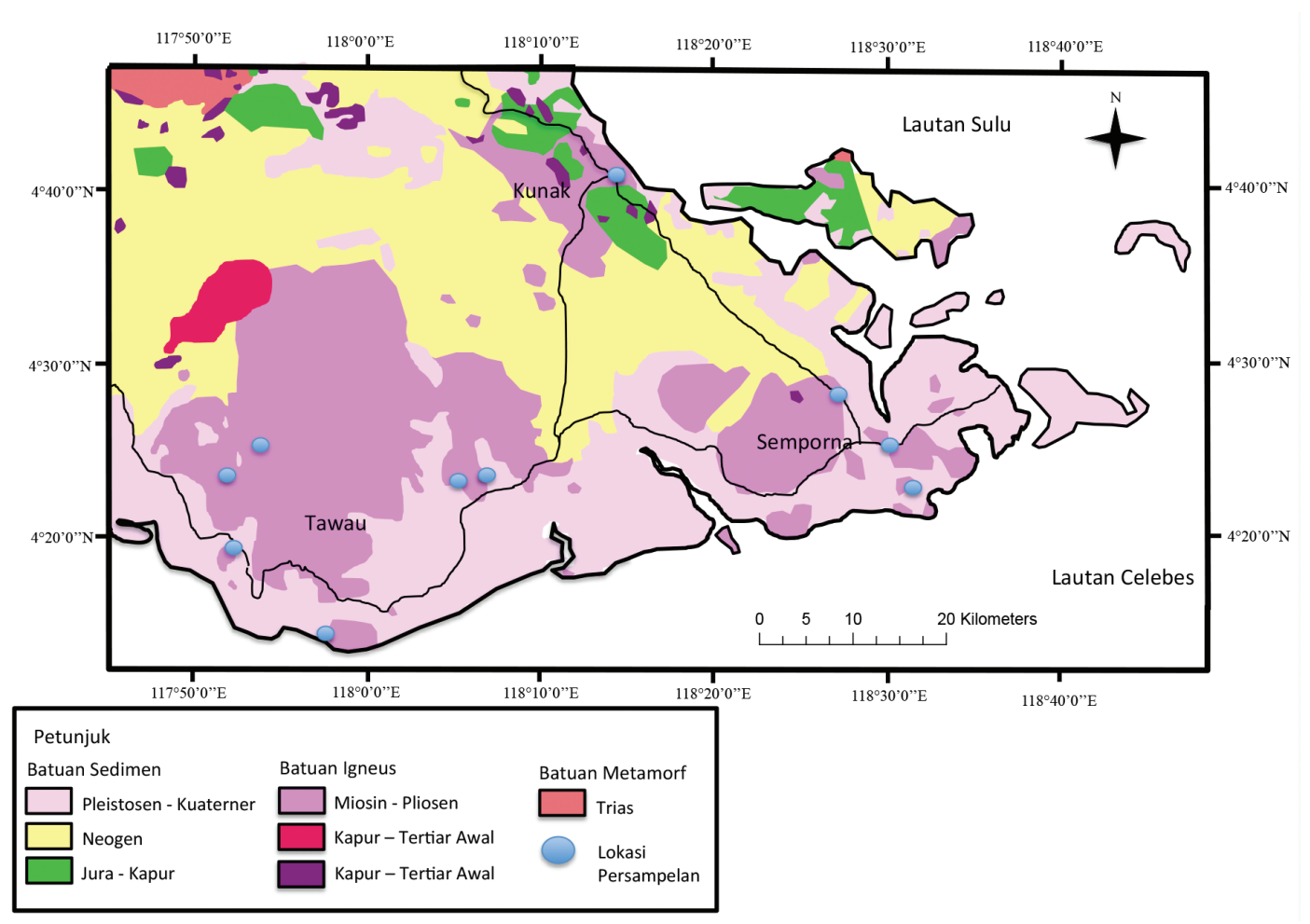

RAJAH 1. Peta geologi Semenanjung Semporna dan lokasi persampelan batuan volkanik 
tertua di Semenanjung Semporna adalah Kompleks Darvel Bay dan Formasi Chert-Spilite yang terdiri daripada peridotit-serpentinit, gabro, basalt, rijang dan batu pasir serta syal turbidit yang merupakan sebahagian daripada jujukan? ofiolit. Korelasi yang ditunjukkan antara jujukan?/ batuan ofiolit di kawasan Darvel Bay dengan blok-blok ofiolit di bahagian utara Semenanjung Semporna telah ditafsirkan sebagai sebahagian daripada kerak lautan kuno yang secara amnya berusia Kapur berdasarkan beberapa penentuan usia batuan igneus dan juga fosil daripada lapisan rijang (Graves et al. 2000; Hutchison 2005; Junaidi \& Basir 2013, 2012; Shariff \& Sanudin 1995).

\section{BAHAN DAN KAEDAH}

Kajian ini dijalankan di sekitar Semenanjung Semporna yang terbahagi kepada 3 kawasan iaitu Tawau, Semporna dan Kunak. Hasil persampelan batuan volkanik terdiri daripada 6 sampel batuan volkanik di Tawau, 4 sampel daripada Semporna dan 1 sampel untuk bahagian Kunak. Kesemua sampel yang dipilih adalah batuan segar. Memandangkan kebanyakan batuan tersebut ialah bersaiz besar, sampel yang diambil ditrim dan dipotong ke saiz yang lebih kecil berukuran $4 \mathrm{~cm} \times 2 \mathrm{~cm}$. Kesemua sampel dihantar ke ACME Analytical Laboratories, Ltd., di Vancouvar, Kanada untuk analisis geokimia unsur major dan nadir bumi (Jadual 1). Untuk analisis unsur major

JADUAL 1. Unsur major and surih batuan Semenanjung Semporna

\begin{tabular}{|c|c|c|c|c|c|c|c|c|c|c|c|}
\hline \multirow{3}{*}{ Sampel } & \multirow{2}{*}{$\begin{array}{c}\text { Kunak } \\
\text { Andesit } \\
\text { Basalt }\end{array}$} & \multicolumn{3}{|l|}{ Tawau } & \multicolumn{7}{|c|}{ Semporna } \\
\hline & & Basalt & $\begin{array}{c}\text { Andesit } \\
\text { Basalt }\end{array}$ & $\begin{array}{c}\text { Andesit } \\
\text { Basalt }\end{array}$ & Andesit & Andesit & Andesit & $\begin{array}{c}\text { Andesit } \\
\text { Basalt }\end{array}$ & Andesit & Andesit & Riolit \\
\hline & $11 \mathrm{~L} 5$ & $18 \mathrm{~L} 5$ & $18 \mathrm{~L} 4$ & 18 L9 & $8 \mathrm{~L} 4$ & $13 \mathrm{~L} 3$ & $14 \mathrm{~L} 1$ & 13L11 & $11 \mathrm{~L} 4$ & 9L5 & 9L2 \\
\hline \multicolumn{12}{|l|}{ Unsur Major } \\
\hline $\mathrm{SiO}_{2}(\mathrm{wt} \%)$ & 52.25 & 48.1 & 54.2 & 53.28 & 58.17 & 57.62 & 64.24 & 53.16 & 60.3 & 57.3 & 74.8 \\
\hline $\mathrm{TiO}_{2}$ & 2.21 & 2.09 & 0.80 & 1.78 & 0.48 & 0.61 & 0.82 & 0.68 & 0.87 & 0.87 & 0.44 \\
\hline $\mathrm{Al}_{2} \mathrm{O}_{3}$ & 14.92 & 15.62 & 18.52 & 14.85 & 16.02 & 17.65 & 21.58 & 18.04 & 15.54 & 17.07 & 13.29 \\
\hline $\mathrm{FeO}^{*}$ & 13.22 & 11.62 & 9.00 & 12.17 & 6.27 & 7.50 & 2.11 & 9.73 & 7.3 & 7.35 & 3.01 \\
\hline $\mathrm{MnO}$ & 0.15 & 0.15 & 0.14 & 0.15 & 0.09 & 0.12 & 0.00 & 0.18 & 0.16 & 0.15 & 0.04 \\
\hline $\mathrm{MgO}$ & 5.67 & 6.41 & 3.80 & 5.5 & 3.26 & 3.29 & 0.04 & 4.04 & 1.96 & 2.48 & 0.20 \\
\hline $\mathrm{CaO}$ & 6.69 & 9.11 & 8.88 & 7.34 & 5.76 & 7.18 & 0.13 & 8.28 & 5.03 & 6.70 & 0.24 \\
\hline $\mathrm{Na}_{2} \mathrm{O}$ & 3.08 & 3.01 & 2.28 & 3.32 & 2.68 & 2.50 & 0.04 & 2.67 & 4.14 & 2.81 & 3.02 \\
\hline $\mathrm{K}_{2} \mathrm{O}$ & 0.22 & 1.23 & 1.24 & 1.11 & 2.01 & 1.57 & 0.19 & 1.30 & 1.85 & 2.04 & 2.83 \\
\hline $\mathrm{P}_{2} \mathrm{O}_{5}$ & 0.14 & 0.32 & 0.13 & 0.24 & 0.10 & 0.11 & 0.26 & 0.19 & 0.25 & 0.30 & 0.05 \\
\hline LOI & 1.20 & 2.00 & 0.80 & 0.00 & 5.00 & 1.70 & 10.40 & 1.50 & 2.40 & 2.80 & 1.90 \\
\hline Jumlah & 99.75 & 99.66 & 99.79 & 99.74 & 99.84 & 99.85 & 99.81 & 99.77 & 99.8 & 99.87 & 99.82 \\
\hline \multicolumn{12}{|c|}{ Unsur Surih (ppm) } \\
\hline $\mathrm{Ba}$ & 77 & 281 & 169 & 232 & 267 & 328 & 663 & 233 & 392 & 281 & 947 \\
\hline $\mathrm{Cs}$ & 0.1 & 0.8 & 1.7 & 1 & 4.4 & 3.7 & 1.7 & 2.7 & 3.3 & 1.7 & 18.9 \\
\hline $\mathrm{Nb}$ & 7.6 & 29 & 2.2 & 20 & 2.4 & 2.2 & 4.4 & 1.4 & 4.8 & 3.3 & 5.4 \\
\hline $\mathrm{Rb}$ & 2.7 & 27.2 & 42.9 & 32.3 & 74.7 & 69.7 & 12 & 44.7 & 61.5 & 40.4 & 57.7 \\
\hline $\mathrm{Sr}$ & 165.9 & 366.9 & 245.3 & 293 & 326.5 & 319.9 & 431.6 & 35.5 & 239.9 & 340.3 & 163.1 \\
\hline $\mathrm{Ta}$ & 0.5 & 1.8 & 0.2 & 1.3 & 0.2 & 0.2 & 0.3 & 0.1 & 0.3 & 0.1 & 0.4 \\
\hline $\mathrm{Th}$ & 1.5 & 2.4 & 4.7 & 3.1 & 6.6 & 5.9 & 8.4 & 4.6 & 6.2 & 3.5 & 7.7 \\
\hline $\mathrm{U}$ & 0.1 & 0.4 & 0.9 & 0.8 & 1.5 & 1.3 & 3.8 & 1 & 1.6 & 0.9 & 1.9 \\
\hline V & 160 & 234 & 268 & 139 & 144 & 165 & 192 & 184 & 108 & 131 & 19 \\
\hline $\mathrm{Zr}$ & 127.9 & 137.7 & 65.2 & 130.2 & 86 & 84.1 & 118.3 & 63.4 & 157.8 & 102.3 & 195.5 \\
\hline $\mathrm{Y}$ & 27 & 23.1 & 21.1 & 20.8 & 11.6 & 33.7 & 214.7 & 16 & 38.4 & 32.6 & 39.6 \\
\hline $\mathrm{La}$ & 6.4 & 16.9 & 12.3 & 13.4 & 14.3 & 24.6 & 22.9 & 13.5 & 22.9 & 17.2 & 22.7 \\
\hline $\mathrm{Ce}$ & 13.3 & 33.3 & 25.2 & 25.9 & 27.3 & 31.8 & 54.7 & 28.1 & 42.2 & 36.9 & 45.4 \\
\hline $\operatorname{Pr}$ & 2.34 & 4.38 & 3.18 & 3.41 & 3.19 & 4.26 & 8.55 & 3.59 & 5.71 & 4.7 & 5.78 \\
\hline $\mathrm{Nd}$ & 13 & 18.6 & 13.7 & 15.7 & 12.6 & 17.6 & 51.7 & 15.6 & 24.3 & 20 & 23.8 \\
\hline $\mathrm{Sm}$ & 5.11 & 4.67 & 3.2 & 4.39 & 2.55 & 3.48 & 28.2 & 3.11 & 5.72 & 4.9 & 5.74 \\
\hline $\mathrm{Eu}$ & 1.7 & 1.66 & 0.94 & 1.47 & 0.68 & 1.01 & 9.94 & 1.04 & 1.61 & 1.5 & 1.29 \\
\hline $\mathrm{Gd}$ & 6.39 & 5.26 & 3.47 & 5.07 & 2.34 & 4.05 & 41.89 & 3.06 & 6.39 & 5.74 & 6.28 \\
\hline Dy & 5.72 & 4.64 & 3.76 & 4.61 & 1.98 & 3.89 & 37.66 & 2.91 & 6.59 & 5.72 & 6.55 \\
\hline Ho & 1.06 & 0.85 & 0.74 & 0.86 & 0.4 & 0.88 & 7.97 & 0.64 & 1.36 & 1.18 & 1.42 \\
\hline $\mathrm{Er}$ & 2.81 & 2.5 & 2.2 & 2.21 & 1.38 & 2.68 & 22.77 & 1.89 & 4.31 & 3.6 & 4.62 \\
\hline $\mathrm{Tm}$ & 0.36 & 0.3 & 0.29 & 0.27 & 0.17 & 0.36 & 3.04 & 0.25 & 0.6 & 0.5 & 0.63 \\
\hline $\mathrm{Yb}$ & 2.35 & 2.01 & 1.94 & 1.79 & 1.26 & 2.26 & 19.15 & 1.68 & 3.98 & 3.4 & 4.36 \\
\hline $\mathrm{Lu}$ & 0.32 & 0.27 & 0.31 & 0.24 & 0.17 & 0.36 & 3.01 & 0.26 & 0.62 & 0.51 & 0.69 \\
\hline
\end{tabular}


$\left(\mathrm{SiO}_{2}, \mathrm{TiO}_{2}, \mathrm{Al}_{2} \mathrm{O}_{3}, \mathrm{Fe}_{2} \mathrm{O}_{3}, \mathrm{MnO}, \mathrm{MgO}, \mathrm{CaO}, \mathrm{Na}_{2} \mathrm{O}, \mathrm{K}_{2} \mathrm{O}\right.$ dan $\mathrm{P}_{2} \mathrm{O}_{5}$ ), batuan terlebih dahulu dijadikan serbuk lalu dicampurkan dengan serbuk litium tetraborat. Campuran ini dimasukkan ke dalam bekas platinum lalu dipanaskan pada suhu 1100 hingga $1200^{\circ} \mathrm{C}$.

Cecair panas campuran batuan dan lithium tetraborat dibawa keluar dan dituang di dalam acuan ' glass bead' dan dibiarkan sejuk. Sebatian tersebut dianalisis menggunakan mesin Philip PW 1404/10 spektrometri pendarflour sinar-X (XRF). Analisis spektrometri emisi aruhan plasma (ICPMS) digunakan untuk menganalisis unsur surih dan unsur nadir bumi (Jadual 1). Sebanyak 0.2 g sampel dicernakan bersama Litium metaborat/tetraborat dan asid nitrik untuk penentuan unsur nadir bumi dan refraktori. Manakala untuk unsur metal dan unsur terharga (precious elements), 0.5 g sampel dicernakan di dalam Aqua Regia lalu dianalisis menggunakan ICP-MS. Anggaran kejituan untuk XRF bagi unsur major ialah kurang dari 3\%, manakala unsur surih untuk ICP-MS ialah kurang daripada 7.5\%.

\section{KEPUTUSAN DAN PERBINCANGAN}

\section{GEOKIMIA BATUAN VOLKANIK}

Berdasarkan kepada pengelasan TAS (Le Bas et al. 1986), batuan volkanik Semenanjung Semporna terbahagi kepada basalt, andesit basalt, andesit dan riolit (Rajah 2(a)). Pengelasan Winchester dan Floyd (1977) untuk 2 sampel batuan Tawau (LOI; 5\% dan 10\%) menunjukkan pengelasan batuan andesit (Rajah 2(b)). Nilai kandungan LOI yang tinggi ini mungkin disebabkan oleh pengaruh perubahan hidroterma yang berdekatan dengan kawasan cerapan. Hasil cerapan tangan menunjukkan batuan volkanik ialah berbutir halus dan sebahagian batuan bertekstur porfiritik. Untuk keratin nipis, keseluruhan batuan menunjukkan tekstur porfiritik dan afenit dengan matriks yang halus. Batuan mafik lebih dominan mineral seperti olivin, klinopiroksen, ortopiroksen, plagioklas dan Fe-Ti oksida. Manakala batuan pertengahan dan felsik lebih kepada plagioklas, hornblend, K-feldspar dan kuarza. Batuan volkanik ini turut tergolong dalam pengelasan subalkali/ tholeitik (Rajah 2). Batuan basalt mempunyai peratusan $\mathrm{SiO}_{2} 48.10 \%$, andesit basalt antara 52.25-54.20\%, manakala andesit mempunyai kandungan $\mathrm{SiO}_{2}$ sebanyak 57.30-61.46\% $\mathrm{SiO}_{2}$ dan riolit ialah $74.80 \% \mathrm{SiO}_{2}$.

Gambarajah Harker bagi beberapa unsur major batuan volkanik menunjukkan korelasi negatif oleh $\mathrm{Fe}_{2} \mathrm{O}_{3}, \mathrm{MgO}, \mathrm{CaO}$ dan $\mathrm{TiO}_{2}$ terhadap $\mathrm{SiO}_{2}$ (Rajah 3). $\mathrm{Al}_{2} \mathrm{O}_{3}$ pula memperlihatkan tren lemah yang hampir selari dengan penurunan $\mathrm{SiO}_{2}$. Korelasi negatif yang ditunjukkan oleh $\mathrm{Fe}_{2} \mathrm{O}_{3}, \mathrm{MgO}$ dan $\mathrm{CaO}$ terhadap $\mathrm{SiO}_{2}$ ini mungkin disebabkan oleh penghabluran berperingkat dan pengurangan mineral plagioklas dan mineral-mineral Fe-Ti seperti piroksen (lihat contoh Mohd Rozi Umor et al. 2012). Unsur surih Rb memperlihatkan sedikit tren peningkatan dengan peningkatan $\mathrm{SiO}_{2}$ bagi andesit basalt hingga andesit (tiada tren untuk basalt dan riolit), manakala unsur Ba jelas menunjukkan peningkatan terhadap $\mathrm{SiO}_{2}$ dari andesit ke riolit (kecuali basalt) (Rajah 3). Unsur surih Sr pula menunjukkan tren yang tidak seragam terhadap $\mathrm{SiO}_{2}$ mungkin kesan daripada proses perubahan batuan (luluhawa) (Rajah 3). Pemerhatian unsur surih V dan Sc (Rajah tidak ditunjukkan) menunjukkan tren yang menurun untuk unsur $\mathrm{V}$ (basalt ke andesit) dan tidak seragam untuk unsur Sc. Ini mungkin disebabkan piroksen lebih memainkan peranan yang penting terhadap mafik (Ciborowski et al. 2013) berbanding batuan pertengahan dan felsik. Unsur Zr, Y, dan Nb turut menunjukkan tren tidak seragam kecuali unsur Ce (Rajah tidak ditunjukkan). Ini mungkin disebabkan oleh pengfraksian mineral aksesori tidak begitu penting di dalam magma selain mineral monazit (Estrade et al. 2014).

Berdasarkan kepada plot gambarajah labah-labah unsur tidak serasi yang dinormalkan terhadap Mantel Primitif (McDonough \& Sun 1995), majoriti batuan volkanik Semenanjung Semporna menunjukkan pengayaan pada Unsur Litofil Ion Besar (LILE; Rb, Sr, Ba and K) dengan penyusutan terhadap Unsur Medan Kekuatan
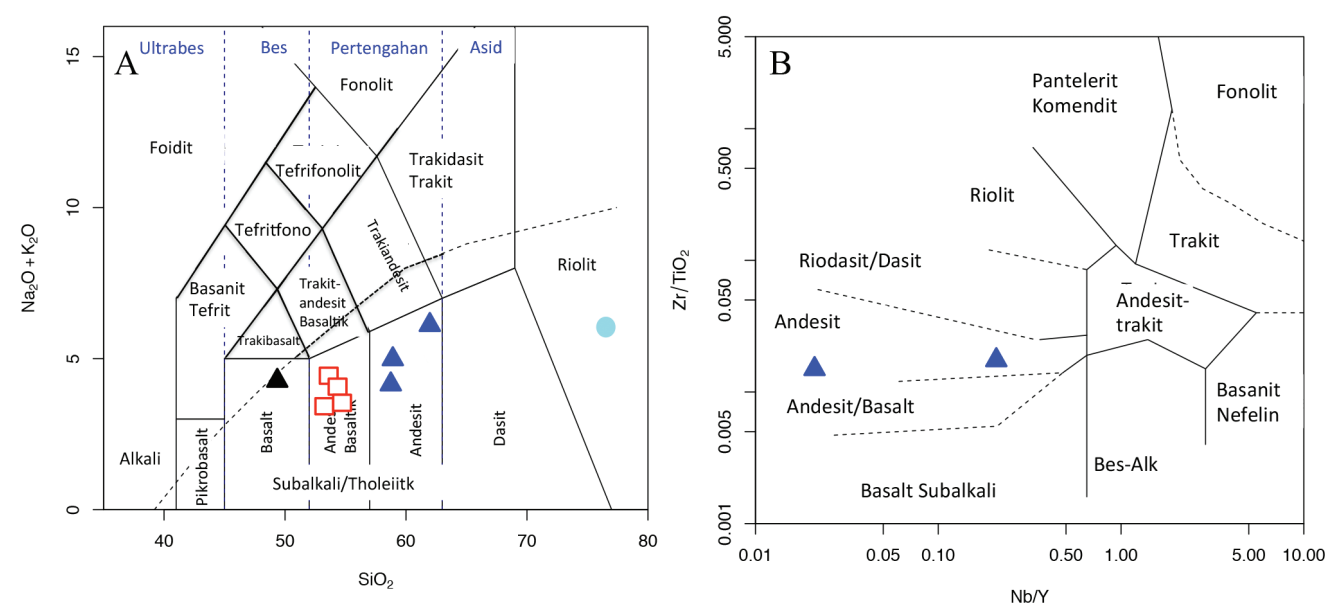

RAJAH 2. (A) Pengelasan TAS (Le Bas et al. 1986) untuk batuan volkanik Semenanjung Semporna, dan (B) Pengelasan $\mathrm{Nb} / \mathrm{Y}$ melawan $\mathrm{Zr} / \mathrm{TiO} 2$ (Winchester \& Floyd 1977) untuk batuan yang mempunyai LOI $>4 \%$ 

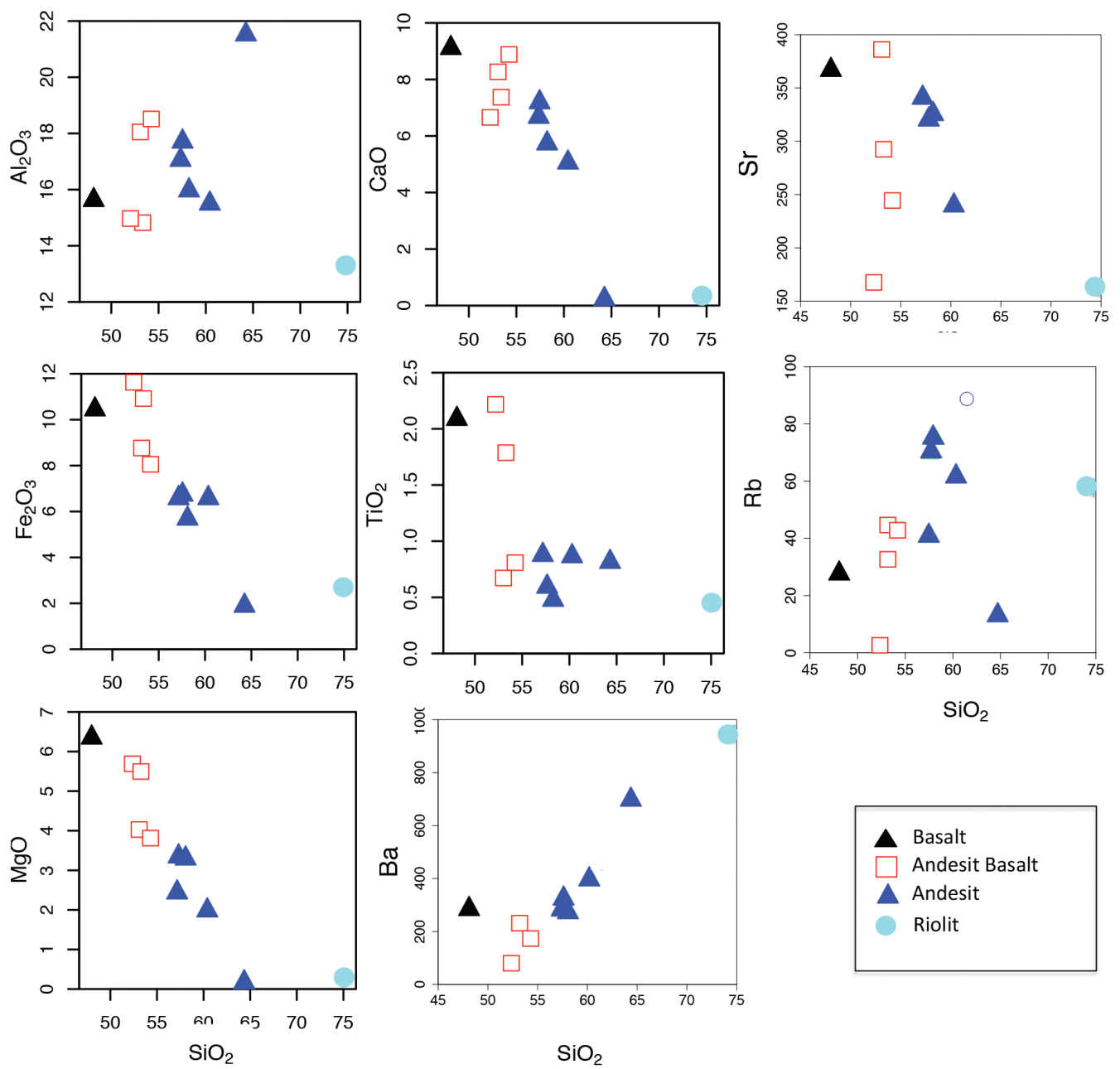

RAJAH 3. Gambarajah Harker untuk unsur major dan surih

Tinggi (HFSE; Ta, Nb, Ta, Zr, Hf, Ti, Y dan Yb) (Rajah 4(a)). Ini menunjukkan hampir kesemua batuan mungkin berasal daripada induk magma yang sama. Pengayaan unsur LILE dan penyusutan HFSE mencadangkan sekitaran magma ialah berkaitan subduksi (Basori et al. 2016; Singh \& Singh 2012; Stolz et al. 1996; Xia \& Li 2019). Ciri ini turut ditunjukkan oleh sifat asalan bidur subduksi yang mempunyai punca mantel tersusut (Singh \& Singh 2012). Interaksi yang berlaku antara baji mantel tersusut dengan leburan hasilan subduksi juga boleh menyebabkan penyusutan HFSE seperti yang perhatikan pada hampir kesemua batuan volkanik di Semenanjung Semporna.

Susutan nilai $\mathrm{Nb}$ untuk majoriti batuan volkanik mungkin disebabkan oleh pengayaan berkaitan subduksi daripada mantel litosfera (Kepezhinkas et al. 1997). Selain daripada itu, terdapat juga tren yang tidak sama jika dibandingkan dengan majoriti batuan volkanik Semenanjung Semporna pada Gambarajah Labah-labah dengan pengayaan pada unsur $\mathrm{Nb}$, Ta dan Ti (sampel 18L5 dan 18L9). Pengayaan pada unsur Nb, Ta dan Ti yang menyerupai 'bentuk-bonggol' dan unsur tidak serasi ini menunjukkan ciri batuan basalt intrakepingan yang menghasilkan magma menyerupai-OIB (Xia \& Li 2019). Sampel 11L5 pula menunjukkan tren yang hampir rata pada Mantel Primitif (penyusutan unsur tidak serasi) yang lebih menyerupai MORB (Stern 2012). Tiga jenis tren yang berbeza ini mungkin disebabkan oleh punca magma yang tidak sama.

Berdasarkan kepada tren Unsur Nadir Bumi (REE), kesemua batuan menunjukkan tren yang hampir sama kecuali batuan andesit basalt (11L5) yang menunjukkan tren yang hampir rata. Tren juga menunjukkan Unsur Nadir Bumi Ringan (LREE) adalah lebih mengalami pengayaan berbanding Unsur Nadir Bumi Berat (HREE) untuk majoriti batuan volkanik Semenanjung Semporna. Pengayaan LREE boleh disebabkan oleh leburan separa tahap rendah daripada mantel primitif (Wulaningsih et al. 2013). Tren HREE yang hampir rata pula menunjukkan siri magma tidak mengalami proses pengfraksian yang dalam (Winter 2001). Nilai REE telah dinormalkan berdasarkan Kondrit REE mengikut Boynton (1984).

Selain daripada itu, kebanyakan batuan turut menunjukkan nilai Eu anomali negatif kecuali beberapa batuan yang menunjukkan sedikit nilai Eu anomali positif. Batuan riolit menunjukkan nilai Eu anomali negatif yang paling ketara antara kesemua batuan. Nilai Eu anomali negatif semakin berkurangan dari basalt ke riolit. Nilai $\mathrm{Eu}$ anomali negatif ialah disebabkan oleh pengfraksian 

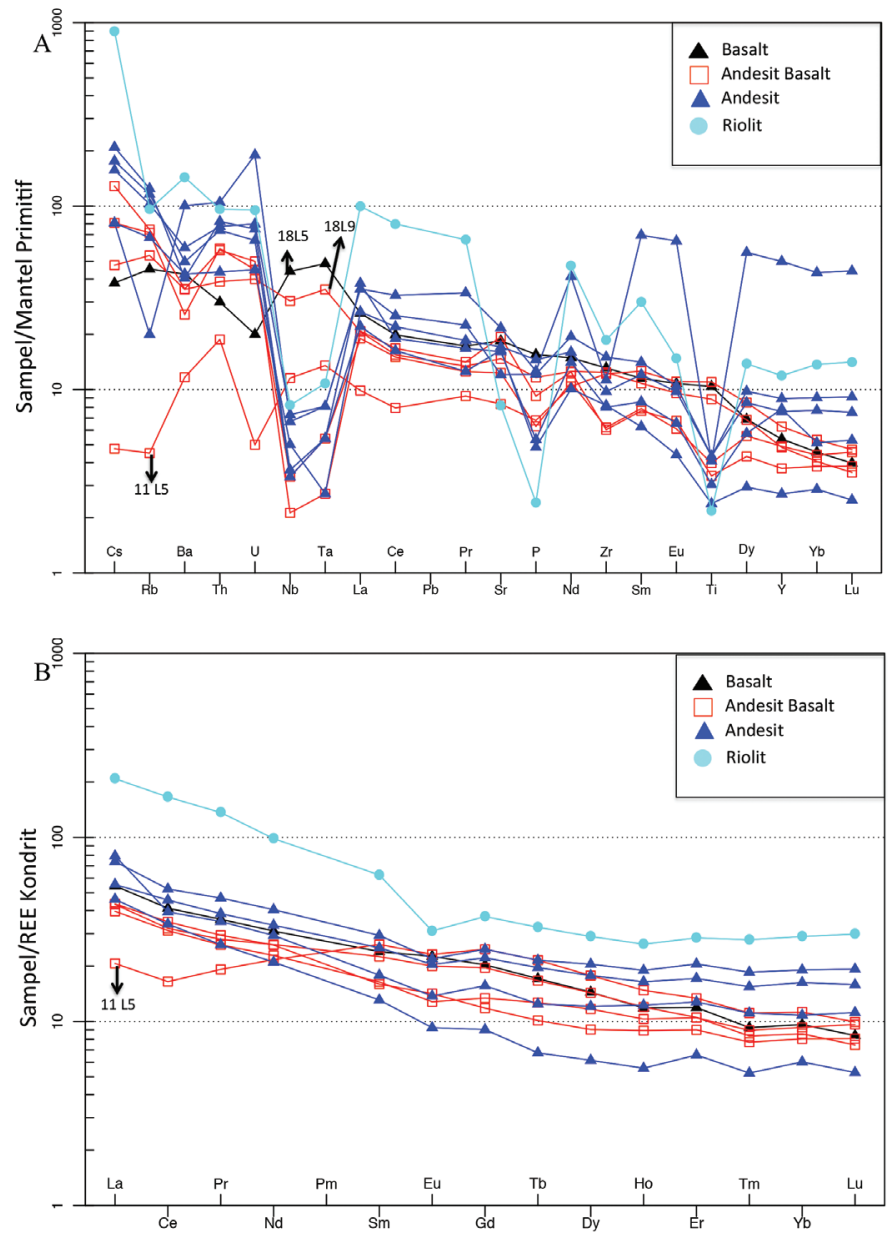

RAJAH 4. (a) Gambarajah labah-labah dan (b) REE batuan volkanik Semenanjung Semporna

mineral plagioklas (Khairil \& Umor 2013; Yu et al. 2019), manakala nilai Eu anomali positif menunjukkan penumpukan mineral plagioklas di dalam magma (Tang et al. 2017). Ini menunjukkan penghabluran fraksinasi plagioklas memainkan peranan utama dalam proses pembezaan pada batuan volkanik Semenanjung Semporna.

\section{SEKITARAN TEKTONIK}

Unsur surih dan unsur nadir bumi selalu digunakan bersama sebagai diskriminasi untuk sekitaran tektonik (Pearce 1996; Pearce \& Cann 1973). Berdasarkan kepada Rajah Ti/Y melawan Zr/Y (Rajah 5(a)), batuan mafik (basalt, 18L5; dan andesit basalt: 18L9 dan 11L5) tergolong dalam basalt dalam-kepingan, manakala batuan yang selebihnya dikategorikan sebagai basalt pinggir kepingan. Plot $\mathrm{Zr}$ melawan $\mathrm{Zr} / \mathrm{Y}$ (Rajah 5(b)) pula menunjukkan batuan volkanik Semenanjung Semporna boleh dibahagikan kepada sekitaran basalt dalam-kepingan dan gabungan sekitaran di antara basalt arka kepulauan dan basalt permatang tengah lautan. Pengelasan sekitaran tektonik yang seterusnya membahagikan batuan mafik (basalt, 18L5; dan andesit basalt: 18L9 dan 11L5) kepada lava dalam kepingan (Rajah 5(c)) dan sekitaran benua (Rajah 5(d)). Batuan volkanik Semenanjung Semporna yang selebihnya tergolong dalam sekitaran lava arka kepulauan (Rajah 5(c)) dan sekitaran di antara pemuaian pusat lautan dan orogeni (Rajah 5(d)).

Sekitaran tektonik untuk batuan yang mempunyai kaitan-subduksi juga disokong oleh Gambarajah LabahLabah (Rajah 4(a)) dengan penyusutan unsur-unsur $\mathrm{Nb}$, Ta dan Ti. Selain daripada itu, batuan yang menyerupai-OIB (pengayaan unsur Nb, Ta dan Ti) (basalt, 18L5; andesit basalt 18L9) dan andesit basalt (11L5) yang mempunyai ciri-ciri MORB (tren Mantel primitif dan REE yang lebih rata) turut menunjukkan perbezaan yang ketara dengan lebih tertumpu kepada sekitaran dalam kepingan. Proses subduksi oleh Laut Celebes yang berlaku semasa usia Miosen (Chiang 2002) mungkin telah menyebabkan berlakunya pembentukan batuan berkaitan-subduksi. Hasil daripada proses subduksi ini turut menyebabkan pengalir lapisan astenosfera terhadap lapisan litosfera yang menipis (Chiang 2002) lalu menghasilkan magma yang menyerupai-OIB (Macpherson et al. 2010). Batuan Arka Sulu yang mempunyai ciri-ciri NMORB/toleiit arka kepulauan (IAT) lebih tertumpu di bahagian Tenggara Arka Sulu (Spadea et al. 1996, 1991) berbanding tempat lain di Sulu. Oleh sebab itu, kehadiran andesit basalt yang mempunyai ciri-ciri MORB mungkin hasil daripada pemuaian Tenggara Lautan Sulu (Hutchison 1992). 

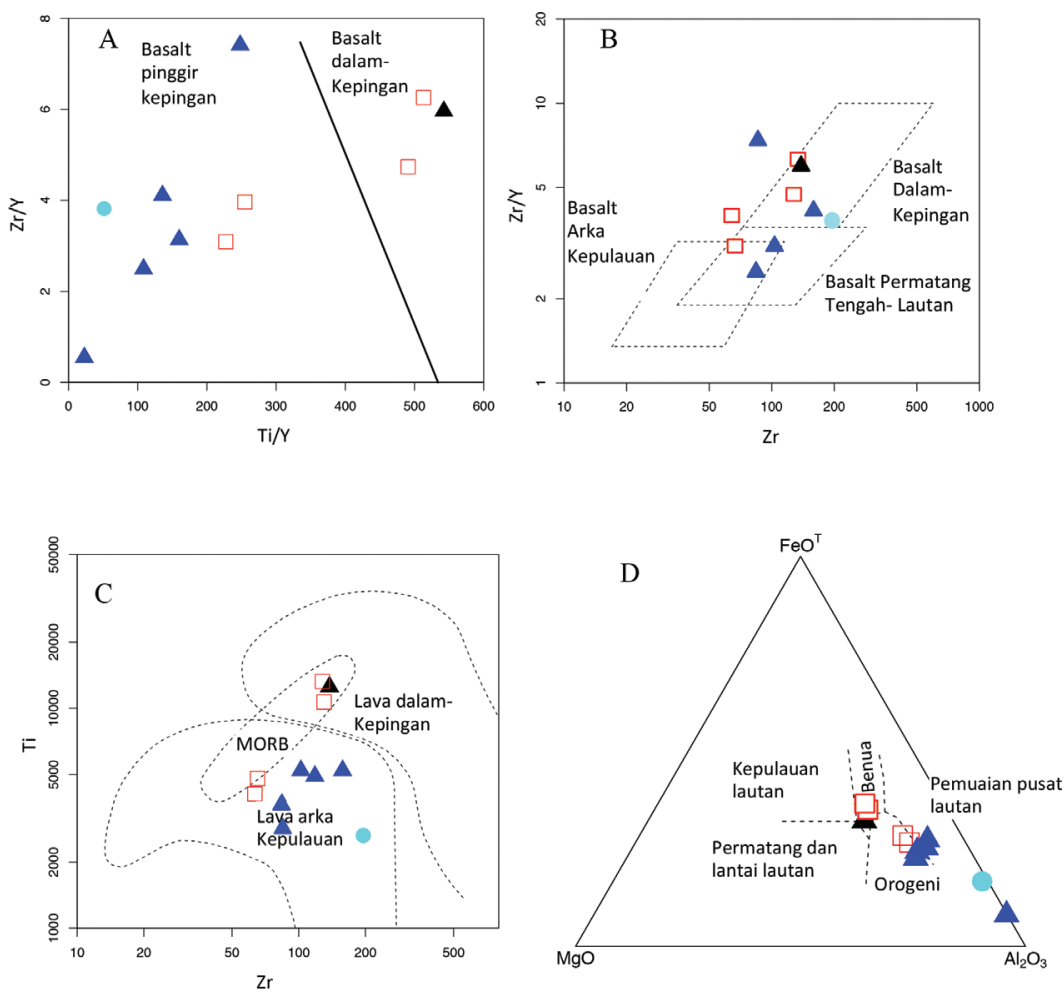

RAJAH 5. (a) Plot Ti/Y melawan Zr/Y (Pearce \& Gale 1977), (b) Plot Zr melawan Zr/Y (Pearce \& Norry 1979),

(c) Plot $\mathrm{Zr}$ melawan $\mathrm{Ti}$ (Pearce 1982) dan, (4) Segitiga $\mathrm{FeO}^{\mathrm{T}}, \mathrm{MgO}_{\text {dan }} \mathrm{Al}_{2} \mathrm{O}_{3}$ (Pearce et al. 1977)

\section{KESIMPULAN}

Batuan volkanik berusia Neogen di Semenanjung Semporna boleh dikelaskan sebagai subalkali/tholeitik dan dibahagi kepada basalt, andesit basalt, andesit dan riolit. Berdasarkan kepada unsur-unsur major dan surih, magma Semenanjung Semporna mengalami penghabluran berperingkat yang dikawal oleh mineral plagioklas, piroksen dan oksida Fe-Ti. Selain daripada itu, tren pada mantel primitif dan REE turut menunjukkan batuan volkanik Semenanjung Semporna terbahagi kepada ciri-ciri kaitan-subduksi, menyerupai-OIB dan MORB. Sekitaran tektonik turut menunjukkan kebanyakan batuan volkanik berkaitan-subduksi di Semenanjung Semporna tergolong dalam sekitaran lava arka kepulauan dan kombinasi orogeni dan pemuaian pusat kepulauan. Batuan volkanik menyerupai-OIB dan MORB pula lebih kepada sekitaran basalt dalam-kepingan dan lava dalamkepingan yang terbentuk di sekitaran benua (Segitiga $\mathrm{FeO}^{\mathrm{T}}-\mathrm{MgO}-\mathrm{Al}_{2} \mathrm{O}_{3}$ ).

\section{PENGHARGAAN}

Penghargaan ditujukan kepada Universiti Malaya dan Universiti Malaysia Kelantan atas pertolongan daripada segi sokongan moral, kewangan dan kemudahan alatan. Selain itu, penghargaan turut diberikan kepada TamanTaman Sabah atas pertolongan dan kerjasama semasa berada di Taman Bukit Tawau, Sabah. Geran penyelidikan untuk membantu penerbitan dan projek ini adalah GUP2017-083.

\section{RUJUKAN}

Balaguru, A. \& Nichols, G. 2004. Tertiary stratigraphy and basin evaluation, southern Sabah (Malaysian Borneo). Journal of Asian Earth Sciences 23: 537-554.

Basori, M.B.I., Zaw, K., Meffre, S. \& Large, R.R. 2016. Geochemistry, geochronology, and tectonic setting of early Permian ( $290 \mathrm{Ma})$ volcanic-hosted massive sulphide deposits of the Tasik Chini district, Peninsular Malaysia. International Geology Review 58(8): 1-20.

Boynton, W.V. 1984. Geochemistry of the rare earth elements: Meteorite studies. In Rare Earth Element Geochemistry, edited by Henderson, P. Amsterdam: Elsevier.

Chiang, K.K. 2002. Geochemistry of the Cenozoic igneous rocks of Borneo and tectonic implications. PhD Thesis, University of London. p. 364 (Unpublished).

Chung, K.W., Sum, C.W. \& Abd. Hadi A. Rahman. 2015. Stratigraphic succession and depositional framework of the Sandakan Formation. Sabah. Sains Malaysiana 44(7): 931-940.

Ciborowski, T.J.R., Kerr, A.C., McDonald, I., Ernst, R.E. \& Minifie, M.J. 2013. The geochemistry and petrogenesis of the Blue Draw Metagabbro. Lithos 174: 271-290.

Estrade, G., Salvi, S., Béziat, D., Rakotovao, S. \& Rakotondrazafy, R. 2014. REE and HFSE mineralization in peralkaline granites of the Ambohimirahavavy alkaline complex, Ampasindava peninsula, Madagascar. Journal of African Earth Sciences 94: 141-155.

Gorring, M.L. \& Kay, S.M. 2001. Mantle processes and sources of Neogene slab window magmas from southern Patagonia, Argentina. Journal of Petrology 42: 1067-1094.

Graves, J.E., Hutchison, C.S., Bergman, S.C. \& Swauger, D.A., 2000. Age and MORB geochemistry of the Sabah ophiolite 
basement. Bulletin of the Geological Society of Malaysia 44: 151-158.

Hall, R. 2002. Cenozoic geological and plate tectonic evolution of SE Asia and the SW Pacific: Computer-based reconstructions, model and animations. Journal of Asian Earth Sciences, Special Issue 20(4): 353-431.

Hall, R. 1996. Reconstructing cenozoic SE Asia. In Tectonic Evolution of SE Asia, edited by Hall, R. \& Blundell, D.J. Geological Society of London Special Publication 106: 153-184.

Hall, R. \& Wilson, M.E.J. 2000. Neogene sutures in eastern Indonesia. Journal of Asian Earth Sciences 18(6): 787-814.

Hutchison, C.S. 2005. Geology of North-West Borneo (Sarawak, Brunei and Sabah). Amsterdam: Elsevier.

Hutchison, C.S. 1992. The Southeast Sulu Sea, a Neogene marginal basin with outcropping extentions in Sabah. Bulletin of the Geological Society of Malaysia 32: 89-108.

Junaidi Asis \& Basir Jasin. 2015. Miocene larger benthic foraminifera from the Kalumpang Formation in Tawau, Sabah. Sains Malaysiana 44(10): 1397-1405.

Junaidi Asis \& Basir Jasin. 2013. Aptian to Turonian radiolarians from chert blocks in the Kuamut Melange, Sabah, Malaysia. Sains Malaysiana 42(5): 561-570.

Junaidi Asis \& Basir Jasin. 2012. Aptian to Turonian Radiolaria from the Darvel Bay Ophiolite Complex, Kunak, Sabah. Bulletin of the Geological Society of Malaysia 58: 89-96.

Kepezhinskas, P., McDermott, F., Defant, M.J., Hochsteadter, A., Drummond, M.S., Hawkesworth, C.J., Koloskov, A., Maury, R.C. \& Bellon, H. 1997. Trace element and Sr$\mathrm{Nd}-\mathrm{Pb}$ isotopic constrains on a three-component model of Kamchatka Arc petrogenesis. Geochimica et Cosmachimica Acta 61(3): 577-600.

Khairil Izam Selamat Din \& Mohd Rozi Umor. 2013. Geochemical study of Palong Pluton at Negeri SembilanPahang Border. AIP Conference Proceedings 1571: 420-431.

Kirk, H.J.C. 1962. The Geology and Mineral Resources of Semporna Peninsula, North Borneo. Kuching: British Borneo Geology Survey Memoir 14.

Le Bas, M.J., Le Maitre, R.W., Streckeisen, A. \& Zanettin, B. 1986. A chemical classification of volcanic rocks based on the total alkali-silica diagram. Journal of Petrology 27: 745-750.

Leeman, W.P., Smith, D.R., Hildreth, W., Palacz, Z. \& Rogers, N. 1990. Compositional diversity of late Cenozoic basalts in a transect across the southern Washington Cascades: Implications for subduction zone magmatism. Journal of Geophysical Research 95: 19561-19582.

Lim P.S. 1981. Wullersdorf Area, Sabah, Malaysia. Malaysia: Kuching: Geological Survey of Malaysia, Report 15.

Macpherson, C.G., Chiang, K.K., Hall, R., Nowell, G.M., Castillo, P.R. \& Thirlwall, M.F. 2010. Plio-Pleistocene intraplate magmatism from the southern Sulu Arc, Semporna peninsula, Sabah, Borneo: Implications for high- $\mathrm{Nb}$ basalt in subduction zones. Journal of Volcanology and Geothermal Research 190: 25-38.

McDonough, W.F. \& Sun, S.S. 1995. The composition of the Earth. Chemical Geology 67(5): 1050-1056.

Mitchell, A.H.G., Hernandez, L. \& De La Cruz, A.P. 1986. Cenozoic evolution of the Philippine Archipelago. Journal of Southeast Asian Earth Sciences 1: 3-22.

Mohd Rozi Umor, Azman Abd. Ghani \& Hamzah Mohamad. 2012. Batuan volkanik Formasi Semantan di sekitar Gunung Benom, Pahang. Bulletin of the Geological Society of Malaysia 58: 43-48.
Orozco-Esquivel, T., Petrone, C.M., Ferrari, L., Tagami, T. \& Manetti, P. 2007. Geochemical and isotopic variability in lavas from the eastern Trans-Mexican Volcanic Belt: Slabdetachment in a subduction zone with varying dip. Lithos 93: 149-174.

Pearce, J.A. 1996. A User's Guide to Basalt Discrimination Diagrams. In Trace Element Geochemistry of Volcanic Rocks: Applications for Massive Sulphide Exploration, edited by Wyman, D.A. Canada: Geological Association of Canada.

Pearce, J.A. 1982. Trace element characteristics of lavas from destructive plate boundaries. In Andesites, edited by Thorpe, R.S. New York: John Wiley \& Sons.

Pearce, J.A. \& Norry, M.J. 1979. Petrogenetic implications of $\mathrm{Ti}, \mathrm{Zr}, \mathrm{Y}$, and $\mathrm{Nb}$ variations in volcanic rocks. Contributions to Mineralogy and Petrology 69: 33-47.

Pearce, J.A. \& Gale, G.H. 1977. Identification of ore-deposition environment from trace-element geochemistry of associated igneous host rocks. Geological Society London, Special Publication 7: 14-24.

Pearce, J.A. \& Cann, J.R. 1973. Tectonic setting of basic volcanic rocks determined using trace element analyses. Earth and Planetary Science Letters 19: 290-300.

Pearce, T.H., Gorman, B.E. \& Birkett,T.C. 1977. The relationship between major element chemistry and tectonic environment of basic and intermediate volcanic rocks. Earth and Planetary Science Letters 36: 121-132.

Rangin, C. 1989. The Sulu Sea, a back-arc basin setting within a Neogene collision zone. Tectonophysics 161: 119-141.

Sanudin Tahir, Shariff A.K. Omang \& Majeed M. Faisal. 1995. Middle Miocene Volkanic Sequence in Eastern Sabah. Borneo Science 1(1): 9-27.

Sanudin Tahir, Baba Musta \& Ismail Abd. Rahim. 2000 Geological Heritage features of Tawau volcanic sequence, Sabah. Bulletin of the Geological Society of Malaysia 56: $79-85$.

Shariff AK Omang \& Sanudin Hj. Tahir. 1995. Cretaceous and Neogene volcanic lavas of Sabah-origin and tectonic Significance. Bulletin of the Geological Society of Malaysia 38: $21-30$

Shimaoka, A., Imamura, M. \& Kaneoka, I. 2016. Beryllium isotopic systematics in island arc volcanic rocks from northeast Japan: Implications for the incorporation of oceanic sediments into island arc magmas. Chemical Geology 443: 158-172.

Singh, A.K. \& Singh, R.K.B. 2012. Petrogenetic evolution of the felsic and mafic volcanic suite in the Siang window of Eastern Himalaya, Northeast India. Geoscience Frontiers 3(5): 613-634.

Spadea, P., D’Antonio, M. \& Thirlwall, M.F. 1996. Source characteristics of the basement rocks from the Sulu and Celebes Basins (Western Pacific): Chemical and isotopic evidence. Contributions to Mineralogy and Petrology 123(2): 159-176.

Spadea, P., Beccaluva, L., Civetta, L., Coltorti, M., Dostal, J., Sajona, F., Serri, G., Vaccaro, C. \& Zeda, O. 1991. Petrology of basic igneous rocks from the floor of the Sulu Sea. In Proceeding of Ocean Drilling Program 124, edited by Silver, E.A., Rangin, C. \& von Breyman, M.T. Texas: Scientific Results.

Stern, R.J. 2002. Subduction zones. Reviews of Geophysics 40(4): 1012.

Stolz, A.J., Jochum, K.P., Spettel, B. \& Hofmann, A.W. 1996. Fluid- and melt-related enrichment in the subarc mantle: 
Evidence from $\mathrm{Nb} / \mathrm{Ta}$ variations in island-arc basalt. Geology 24(7): 587-590.

Tang, M., McDonough, W.F. \& Ash, R.D. 2017. Europium and strontium anomalies in the MORB source mantle. Geochimica et Cosmochimica Acta 197: 132-141.

Tongkul, F. 1993. Tectonic control on the development of the Neogene basins in Sabah, East Malaysia. In Proceedings Symposium on the Tectonicframework and Energy Resources of the Western Margin of the Pacific Basin, edited by Teh, G.H. Bulletin of the Geological Society of Malaysia, Special Publication 33: 95-103.

Winchester, J.A. \& Floyd,P.A. 1977. Geochemical discrimination of different magma series and their differentiation products using immobile elements. Chemical Geology 20: 325-343.

Winter, J. 2001. An Introduction to Igneous and Metamorphic Petrology. New Jersey: Prentice Hall.

Wulaningsih, T., Humaida, H., Harijoko, A. \& Watanabe, K. 2013. Major element and rare earth elements investigation of Merapi Volcano, Central Java, Indonesia. Procedia Earth and Planetary Science 6: 202-211.

Xia, L. \& Li, X. 2019. Basalt geochemistry as a diagnostic indicator of tectonic setting. Gondwana Research 65: 43-67.

Yu, Z.Q., Chen, W.F., Chen, P.R., Wang, K.X., Fang, Q.C., Tang, X.S. \& Ling, H.F. 2019. Chemical composition and $\mathrm{Sr}$ isotopes of apatite in the Xiangshan A-type volcanic-intrusive complex, Southeast China: New insight into petrogenesis. Journal of Asian Earth Sciences 172: 66-82.
Elvaene James* \& Azman A. Ghani,

Jabatan Geologi, Fakulti Sains

Universiti Malaya

50603 Kuala Lumpur, Wilayah Persekutuan

Malaysia

Junaidi Asis

Fakulti Sains dan Sumber Asli

Universiti Malaysia Sabah

88400 Kota Kinabalu, Sabah

Malaysia

\section{Norbert Simon}

Program Geologi, Pusat Sains Bumi dan Alam Sekitar

Fakulti Sains dan Teknologi

Universiti Kebangsaan Malaysia

43600 UKM Bangi, Selangor Darul Ehsan

Malaysia

*Pengarang untuk surat-menyurat; email: elvaene_anne@yahoo. com

Diserahkan: 20 Mac 2019

Diterima: 15 Ogos 2019 